\title{
Recanalisation of middle cerebral artery occlusion after intra-arterial thrombolysis: different recanalisation grading systems and clinical functional outcome
}

\author{
M Arnold, K Nedeltchev, L Remonda, U Fischer, C Brekenfeld, B Keserve, G Schroth, H P Mattle
}

J Neurol Neurosurg Psychiatry 2005;76:1373-1376. doi: 10.1136/jnnp.2004.055160

See end of article for
authors' affiliations
$\ldots \ldots \ldots \ldots \ldots \ldots \ldots \ldots . . . .$.
Correspondence to:
Professor Heinrich PMattle,
Department of Neurology,
University of Berne,
Freiburgstrasse, Inselspital,
CH-3010 Berne,
Switzerland; heinrich.
mattle@insel.ch
Received
29 September 2004
In revised form
24 January 2005
Accepted 24 January 2005
Background: Different grading systems of arterial recanalisation have never been compared in large series of stroke patients treated with intra-arterial thrombolysis (IAT).

Methods: Clinical and angiographic findings and outcome were analysed in 147 patients with M1 or M2 segment occlusion of the middle cerebral artery treated with IAT. Associations of the thrombolysis in myocardial infarction (TIMI) grading system and the Mori grading system with clinical outcome were compared.

Results: The median NIHSS score on admission was 15 and the mean time from symptom onset to IAT was 242 minutes. After three months the outcome was favourable (defined as modified Rankin scale score $(\mathrm{mRS}) \leqslant 2)$ in 85 patients $(58 \%)$ and poor (mRS 3 to 5$)$ in $44(30 \%)$; 18 patients $(12 \%)$ were dead. Recanalisation was categorised as TIMI grade 0 in 17 patients (12\%), TIMI 1 in 16 (11\%), TIMI 2 in 83 (56\%), and TIMI 3 in $31(21 \%)$. Seventeen patients (12\%) showed Mori grade 0 reperfusion, 16 (1 1\%) Mori 1, 37 (25\%) Mori 2, 46 (31\%) Mori 3, and 31 (21\%) Mori 4. In both TIMI and Mori grading systems, reopening the artery was an independent predictor of a favourable clinical outcome $(p<0.0001)$. When recanalisation was partial, outcome was better in patients with reperfusion $>50 \%$ (Mori 3 ) than in those with reperfusion $<50 \%$ (Mori 2$)(p=0.008)$.

Conclusions: Both TIMI and Mori grading systems are useful for predicting outcome after stroke and IAT. When recanalisation is partial the Mori classification is more refined in giving prognostic information.
$\mathrm{T}$ he association of vessel recanalisation after stroke and clinical outcome has been well documented in several thrombolysis trials. ${ }^{1-5}$ However, to date it has not been shown what degree of recanalisation will be most likely to result in a favourable outcome. Recently, several trials have been designed or carried out in which partial or complete vessel recanalisation is used as an outcome measure to determine the efficacy of new non-pharmacological recanalisation techniques such as transcranial ultrasound or laser or thrombaspiration techniques. ${ }^{6}$ However, recanalisation can only be used as a surrogate marker for outcome when it can be assessed and graded reliably. Large studies comparing different recanalisation grading systems as seen on arteriography are lacking. The thrombolysis in myocardial infarction (TIMI) grading system is widely used in stroke studies, though it was designed to determine vessel recanalisation after myocardial infarction. Furthermore, TIMI grade 2 includes a wide range of partial recanalisation between minimal (TIMI grade 1) and complete (TIMI grade 3$)^{7}$ Another classification was created by Mori, looking at four degrees of reperfusion as seen on arteriography (table 1). ${ }^{8}$ The Mori classification divides the large group of patients with partial reperfusion into two groups: reperfusion of less than $50 \%$ of the territory of the occluded artery (Mori grade 2 ), and reperfusion of more than $50 \%$ (Mori grade 3 ). We hypothesised that the Mori grading system of arterial reperfusion is more refined than the TIMI system in predicting clinical outcome in acute stroke patients with M1 or M2 occlusion of the middle cerebral artery treated with intra-arterial thrombolysis (IAT).

\section{METHODS}

From December 1992 to September 2003, 278 patients with ischaemic stroke were treated with IAT at our institution.
Several aspects of some of these patients, including indications for treatment, have been published previously. ${ }^{9-12}$ The 149 patients with occlusions of the M1 or M2 segments of the middle cerebral artery were the focus of this analysis. Their neurological status was assessed on admission by a neurologist using the NIHSS score. ${ }^{13}$ All patients underwent computed tomography (CT) or magnetic resonance imaging (MRI) to exclude cerebral haemorrhage immediately after neurological evaluation. Early parenchymal CT signs of ischaemia were defined according to the criteria of von Kummer et al. ${ }^{14}$ Arteriography was carried out using a transfemoral approach. All patients had four vessel diagnostic arteriography to assess the complete vessel status and collateral circulation, if present.

Urokinase (mean dose, 950000 ; range, 200000 to $1000000 \mathrm{IU})$ was infused directly into or near the proximal end of the occluding thrombus over a period of 60 to 90 minutes. In 20 patients with M1 or M2 occlusion, aspiration or mechanical disruption of the clot or both were carried out in addition to pharmacological thrombolysis. In five patients with persistent occlusion after urokinase infusion, percutaneous transluminal angioplasty of the middle cerebral artery was undertaken using a FastStealth balloon dilatation catheter (Target Therapeutics, Fremont, California, USA) with a balloon diameter of $2 \mathrm{~mm}$. In 16 patients with additional ipsilateral high grade carotid stenosis or occlusion, endovascular treatment of the internal carotid artery with stent placement was carried out before thrombolysis of the middle cerebral artery. These groups were not analysed separately because of the small number of patients.

Abbreviations: IAT, intra-arterial thrombolysis; mRS, modified Rankin scale; NIHSS, National Institutes of Health stroke scale; TIMI, thrombolysis in myocardial infarction grading system 
Table 1 Grading systems for vessel recanalisation on cerebral arteriography

\begin{tabular}{lll}
\hline $\begin{array}{l}\text { Grading } \\
\text { system }\end{array}$ & Grade & Criteria on arteriography \\
\hline TIMI & 0 & $\begin{array}{l}\text { No recanalisation } \\
\text { Minimal recanalisation }\end{array}$ \\
& 1 & $\begin{array}{l}\text { Partial recanalisation } \\
\text { Complete recanalisation }\end{array}$ \\
Mori & 0 & $\begin{array}{l}\text { No reperfusion } \\
\text { Minimal reperfusion } \\
\text { Reperfusion of less than } 50 \% \text { of the territory of the } \\
\text { occluded artery } \\
\text { Reperfusion of more than } 50 \% \text { of the territory of the } \\
\end{array}$ \\
& 2 & $\begin{array}{l}\text { occluded artery } \\
\text { Complete reperfusion }\end{array}$ \\
\hline
\end{tabular}

Mori, classification by Mori and coworkers ${ }^{7}$; TIMI, thrombolysis in myocardial infarction.

Treatment effect was documented by arteriography immediately after IAT. Recanalisation of the middle cerebral artery was classified according to TIMI grades and Mori grades retrospectively by a neuroradiologist (LR or GS) who was blinded to the clinical follow up examinations after three months but not to the initial clinical course of the patient during the hospital admission (table 1). ${ }^{78}$ To assess interobserver agreement on the Mori grading system, a neurologist (UF), who was blinded to the first assessment of the neuroradiologist but not to the clinical findings, reviewed all angiograms with partial recanalisation and classified recanalisation with the Mori grading system. Stroke aetiology was determined using additional investigations as necessary and classified according to TOAST criteria. ${ }^{15}$ Clinical functional outcome was assessed by different neurologists (mostly MA) three months after the stroke by clinical examination using the modified Rankin scale (mRS) ${ }^{16}$ The neurologists were not blinded to the initial patient history. Two patients were lost to follow up at three months and were excluded from the study. Modified Rankin scale (nRS) scores of 0 to 2 were defined as "favourable" and mRS scores of 3 to 5 as a "poor" outcome. Death corresponds to an mRS score of 6
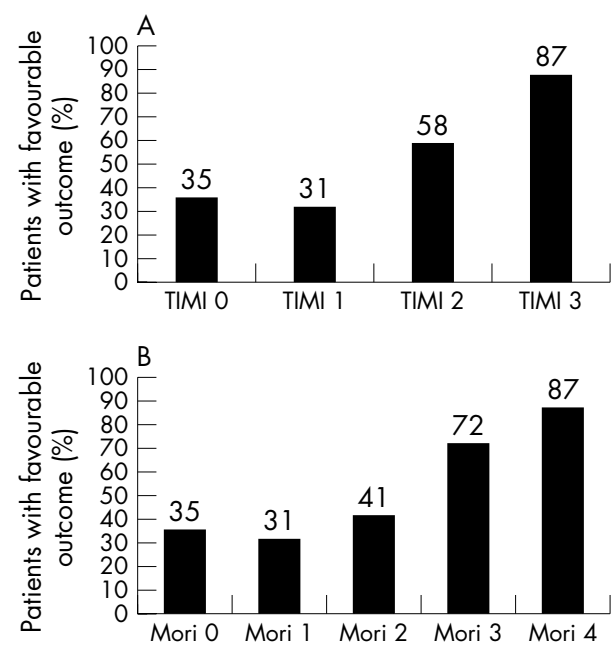

Figure 1 (A) Association of recanalisation measured by thrombolysis in myocardial infarction (TIMI) grading system and clinical outcome. Favourable outcome was defined as a modified Rankin scale score of $\leqslant 2$. (B) Association of reperfusion measured by Mori grading system and clinical outcome. Favourable outcome was defined as a modified Rankin scale score of $\leqslant 2$.

\section{Statistics}

Statistical analysis was carried out with the SPSS ${ }^{\circledR}$ for Macintosh. For comparison of baseline variables between the different recanalisation groups the $\chi^{2}$ or Mann-Whitney tests were used for categorical variables and the KruskalWallis test for continuous variables. For the analysis of predictors of clinical outcome we dichotomised patients into two groups (those with favourable outcome (mRS $\leqslant 2$ ) versus those with poor outcome or death (mRS 3-6)). In addition, a logistic regression analysis with a forward stepwise method was used to determine the independent association of outcome with clinical and radiological factors. The following variables were analysed: age, sex, time from symptom onset to treatment, stroke aetiology, hypertension, diabetes, hypercholesterolaemia, current smoking, initial NIHSS score, hyperdense middle cerebral artery sign, occluded vessel segment, dose of urokinase, and leptomeningeal collaterals. All the analyses were done for both the TIMI and the Mori grading system. Two sided probability (p) values of less than 0.05 were considered significant. Interobserver agreement between the neuroradiologist and the neurologist was analysed using $\kappa$ statistics.

\section{RESULTS}

\section{Baseline demographic data and clinical and radiological findings}

We analysed 147 patients (78 men, 69 women), with a mean (SD) age of 60 (13) years (range 18 to 82), with M1 or M2 segment occlusions of the middle cerebral artery; 108 had Ml occlusions and 39 had M2 occlusions. The median baseline NIHSS score on admission was 15 (range 4 to 24). The mean time from symptom onset to initiation of IAT was $242 \mathrm{~min}$ utes. Sixty seven patients (46\%) showed early parenchymal CT signs of ischaemia. A hyperdense middle cerebral artery sign was noted in 69 patients $(47 \%)$. Presumed stroke aetiologies were cardiac emboli in 85 patients $(58 \%)$, large artery disease in $16(11 \%)$, other reasons in $13(9 \%)$, and undetermined in $33(22 \%)$.

\section{Vessel recanalisation}

TIMI grades

Recanalisation in the 147 patients was categorised as TIMI grade 0 in 17 patients (12\%), TIMI grade 1 in $16(11 \%)$, TIMI 2 in $83(56 \%)$, and TIMI 3 in $31(21 \%)$.

\section{Mori grades}

Mori grade 0 reperfusion was observed inl7 patients ( $12 \%)$, grade 1 in $16(11 \%)$, grade 2 in $37(25 \%)$, grade 3 in $46(31 \%)$, and grade 4 in $31(21 \%)$. Patients classified as Mori grade 0 , 1 , and 4 were identical with patients classified as TIMI grade 0,1 , and 3 .

The interobserver agreement between the neuroradiologist and the neurologist in the differentiation between the Mori grades 2 and 3 was high $(\kappa=0.952)$.

\section{Clinical outcome and complications}

Three months after the stroke mRS was 2 or less in 87 patients $(58 \%)$ indicating a favourable outcome. Forty four patients $(30 \%)$ had a poor outcome (mRS 3 to 5 ) and 18 $(12 \%)$ were dead. Nine patients $(6 \%)$ suffered a symptomatic intracerebral haemorrhage. Four patients $(3 \%)$ had non-lifethreatening extracranial haemorrhages.

\section{Association of vessel recanalisation and clinical outcome}

There were no significant differences in clinical and demographic baseline variables between groups with different recanalisation grades, either for the TIMI or the Mori grading systems (table 2). Outcome was favourable in six of 17 
Table 2 Baseline data of different recanalisation groups

\begin{tabular}{|c|c|c|c|c|c|}
\hline Recanalisation grade & Age (years) & Sex (\% women) & $\begin{array}{l}\text { Initial median NIHSS } \\
\text { score }\end{array}$ & $\begin{array}{l}\text { Time (min) from symptom } \\
\text { onset to treatment }\end{array}$ & $\begin{array}{l}\text { Occluded vessel ( } \% \text { patients } \\
\text { with } M 1 \text { occlusions) }\end{array}$ \\
\hline TIMI $0(n=17)$ & $56(13)$ & $59 \%$ & 14 & $274(48)$ & $59 \%$ \\
\hline TIMI $1(n=16)$ & $63(10)$ & $44 \%$ & 17 & $254(64)$ & $75 \%$ \\
\hline TIMI $2(n=83)$ & $61(9)$ & $45 \%$ & 15 & $242(50)$ & $72 \%$ \\
\hline TIMI $3(n=31)$ & $60(9)$ & $45 \%$ & 16 & $256(72)$ & $84 \%$ \\
\hline Mori $0(n=17)$ & $56(13)$ & $59 \%$ & 14 & $274(48)$ & $59 \%$ \\
\hline Mori $1(n=16)$ & $63(10)$ & $44 \%$ & 17 & $254(64)$ & $75 \%$ \\
\hline Mori $2(n=37)$ & $59(10)$ & $50 \%$ & 16 & $257(46)$ & $72 \%$ \\
\hline Mori $3(n=46)$ & $62(9)$ & $41 \%$ & 15 & $230(55)$ & $71 \%$ \\
\hline Mori $4(n=31)$ & $60(9)$ & $45 \%$ & 16 & $256(72)$ & $84 \%$ \\
\hline
\end{tabular}

patients (35\%) with TIMI grade 0 recanalisation, five of 16 (31\%) with TIMI grade 1, 48 of 83 (58\%) with TIMI grade 2 , and 27 of $31(87 \%)$ with TIMI grade 3 (fig lA).

Six of 17 patients $(35 \%)$ with Mori grade 0 reperfusion, five of $16(31 \%)$ with grade 1,15 of $37(41 \%)$ with grade 2,33 of $46(72 \%)$ with grade 3 , and 27 of $31(87 \%)$ with grade 4 had a favourable outcome as assessed three months after the stroke (fig 1B).

In logistic regression analysis recanalisation as classified by TIMI grades or reperfusion as assessed by Mori grades were independent predictors of a favourable clinical outcome (mRS $\leqslant 2$ ) after three months $(\mathrm{p}<0.0001$ for both grading systems $)$.

Clinical outcome of patients without recanalisation and of patients with minimal recanalisation (TIMI $0 v$ TIMI 1 and Mori $0 v$ Mori 1) did not differ, but partial reperfusion made a significant difference for clinical outcome when it was less than or more than 50\% (Mori $2 v$ Mori 3; $\mathrm{p}=0.008$ ).

\section{DISCUSSION}

This study shows a highly significant independent association of vessel recanalisation and clinical functional outcome using logistic regression analysis for both the TIMI and Mori grading systems. These results are consistent with previous studies. Recanalisation is a powerful predictor of outcome in stroke, as has been shown in patients without treatment and in patients who received intra-arterial or intravenous thrombolysis. ${ }^{4101718}$ Recanalisation is increasingly used as a surrogate marker for efficacy in stroke trials. However, different angiographic grading systems have never been analysed systematically in large patient cohorts. In this study we evaluated the outcome of a series of 147 patients with acute M1 or M2 occlusion of the middle cerebral artery, applying two different angiographic grading systems (TIMI and Mori).

On one side of the spectrum were patients without recanalisation or minimal recanalisation only, based on the high resolution, biplane subtraction angiography (1024x 1024 matrix) of the internal or common carotid artery at the end of IAT therapy. They were classified by both grading systems as TIMI 0 or 1 and Mori 0 or 1 , respectively. Their outcome was favourable in approximately one third of the patients only. Minimal recanalisation or reperfusion (TIMI 1 or Mori 1) did not improve the patient's fate compared with no recanalisation or reperfusion at all (TIMI 0 or Mori 0 ). At the other end of the spectrum were patients with complete recanalisation or reperfusion (TIMI 3 or Mori 4). Their outcome was favourable in $87 \%$. In the large group of patients with partial recanalisation or reperfusion the outcome assessment with the Mori grading system is more refined than the TIMI grading. Mori splits this large group into those with less than $50 \%$ reperfusion (Mori 2) and those with more than $50 \%$ reperfusion (Mori 3). Patients with Mori 2 had a $41 \%$ chance of favourable outcome whereas the chances of Mori 3 patients recovering favourably rose close to the chances of those with complete reperfusion (that is, $72 \%$ ). Therefore, TIMI grade 2 with an overall $58 \%$ chance of a favourable outcome lumps very different patients together. TIMI 2 comprises patients with just a little better recanalisation than minimal to patients with nearly complete recanalisation. Thus the estimate of outcome in TIMI 2 can be crude only.

Neumann-Haefelin and coworkers showed interesting outcome data of stroke patients after intravenous thrombolysis. ${ }^{17}$ They assessed recanalisation in their patients with time of flight MR angiography (MRA). TIMI 1 patients had better outcomes than TIMI 0 patients, which is in contrast to the equal outcome in our series. Their conclusion was that even minimal early recanalisation might be beneficial for some patients. The discrepancy could result from the different methods used to assess the TIMI grades. Time of flight MRA might not be sensitive enough to pick up the slow flow, which is visible in digital subtraction angiography (DSA) of TIMI 1 and therefore would classify a DSA TIMI 1 as MRA TIMI 0 . On the other hand MRA TIMI 1 might correspond already to DSA TIMI 2.

Possible limitations of our study include its retrospective design and incomplete blinding of all the raters who assessed clinical outcome or graded arterial recanalisation on arteriography.

In conclusion, our study indicates that both grading systems, TIMI and Mori, are useful to predict clinical functional outcome three months after stroke caused by middle cerebral artery occlusions. When recanalisation or reperfusion is missing, minimal, or complete, there is no difference between these two grading systems. However, in the frequent case with partial recanalisation or reperfusion, Mori is more refined in giving prognostic information. If recanalisation or reperfusion is used as a surrogate marker for stroke outcome in trials, Mori grading gives additional information to the widely used TIMI classification.

\section{ACKNOWLEDGEMENTS}

We thank Pietro Ballinari, PhD, for statistical advice.

\section{Authors' affiliations}

M Arnold, U Fischer, B Keserue, H P Mattle, Department of Neurology, University of Berne, Berne, Switzerland

K Nedeltchev, L Remonda, C Brekenfeld, G Schroth, Department of Neuroradiology, University Hospital of Berne

Competing interests: none declared.

\section{REFERENCES}

1 Zeumer $\mathrm{H}$, Freitag $\mathrm{HJ}$, Zanella F, et al. Local intra-arterial fibrinolytic therapy in patients with stroke: urokinase versus recombinant tissue plasminogen activator (r-PA). Neuroradiology 1993;35:159-62.

2 Von Kummer R, Holle R, Rosin L, et al. Does arterial recanalization improve outcome in carotid territory stroke? Stroke 1994;26:581-7.

3 Brandt T, von Kummer R, Muller-Kuppers M, et al. Thrombolytic therapy of acute basilar artery occlusion: variables affecting recanalization and outcome. Stroke 1996;27:875-81. 
4 Ueda T, Sakaki S, Kumon $Y$, et al. Multivariable analysis of predictive factors related to outcome at 6 months after intra-arterial thrombolysis for acute ischemic stroke. Stroke 1999;30:2360-5.

5 Takada T, Yasaka M, Minematsu K, et al. Predictors of clinical outcome in patients receiving local intra-arterial thrombolysis without subsequent symptomatic intracranial hemorrhage against middle cerebral artery occlusion. Am J Neuroradiol 2004;25:1796-801.

6 Anon. Major ongoing stroke trials. Stroke 2003;34:e61-72.

7 The Thrombolysis in Myocardial Infarction (TIMI) trial. Phase I findings. TIMI Study Group. N Engl J Med 1985;312:932-6.

8 Mori E, Tabuchi M, Yoshida T, et al. Intracarotid urokinase with thromboembolic occlusion of the middle cerebral artery. Stroke 1988; 19:802-12

9 Gonner F, Remonda L, Mattle H, et al. Local intra-arterial thrombolysis in acute ischemic stroke. Stroke 1998;29:1894-900.

10 Arnold M, Schroth G, Nedeltchev K, et al. Intra-arterial thrombolysis in 100 patients with acute stroke due to middle cerebral artery occlusion. Stroke 2002;33:1828-33

11 Arnold M, Nedeltchev K, Mattle HP, et al. Clinical and radiological predictors of recanalization and outcome in 40 patients with acute basilar artery occlusion treated with intra-arterial thrombolysis. I Neurol Neurosurg Psychiatry 2004;75:857-62

12 Arnold M, Nedeltchev K, Mattle HP, et al. Intra-arterial thrombolysis in 24 consecutive patients with internal carotid artery t-occlusions. I Neurol Neurosurg Psychiatry 2003;74:739-42.

13 Brott T, Adams HP, Olinger CP, et al. Measurements of acute cerebral infarction: a clinical examination scale. Stroke 1989;20:864-70.

14 von Kummer R, Allen KL, Holle R, et al. Acute stroke: usefulness of early CT findings before thrombolytic therapy. Radiology 1997;205:327-33.

15 Adams HP, Bendixen BH, Kappelle $\amalg$, et al. Classification of subtype of acute ischemic stroke. Definitions for use in a multicenter clinical trial. TOAST. Trial of Org 10172 in acute stroke treatment. Stroke 1993;24:35-41.

16 van Swieten JC, Koudstaal PJ, Visser MC, et al. Interobserver agreement for the assessment of handicap in stroke patients. Stroke 1988;19:604-7.

17 Hacke W, Zeumer H, Ferbert A, et al. Intra-arterial thrombolytic therapy improves outcome in patients with acute vertebrobasilar occlusive disease. Stroke 1988;19:1216-22.

18 Neumann-Haefelin T, du Mesnil de Rochemont R, Fiebach JB, et al. Effect of incomplete (spontaneous and postthrombolytic) recanalization after middle cerebral artery occlusion: a magnetic resonance imaging study. Stroke 2004;35:109-14.

\section{Clinical Evidence-Call for contributors}

Clinical Evidence is a regularly updated evidence-based journal available worldwide both as a paper version and on the internet. Clinical Evidence needs to recruit a number of new contributors. Contributors are healthcare professionals or epidemiologists with experience in evidence-based medicine and the ability to write in a concise and structured way.

Areas for which we are currently seeking authors:

- Child health: nocturnal enuresis

- Eye disorders: bacterial conjunctivitis

- Male health: prostate cancer (metastatic)

- Women's health: pre-menstrual syndrome; pyelonephritis in non-pregnant women However, we are always looking for others, so do not let this list discourage you.

\section{Being a contributor involves:}

- Selecting from a validated, screened search (performed by in-house Information Specialists) epidemiologically sound studies for inclusion.

- Documenting your decisions about which studies to include on an inclusion and exclusion form, which we keep on file.

- Writing the text to a highly structured template (about 1500-3000 words), using evidence from the final studies chosen, within 8-10 weeks of receiving the literature search.

- Working with Clinical Evidence editors to ensure that the final text meets epidemiological and style standards.

- Updating the text every six months using any new, sound evidence that becomes available. The Clinical Evidence in-house team will conduct the searches for contributors; your task is simply to filter out high quality studies and incorporate them in the existing text.

- To expand the topic to include a new question about once every 12-18 months.

If you would like to become a contributor for Clinical Evidence or require more information about what this involves please send your contact details and a copy of your CV, clearly stating the clinical area you are interested in, to Klara Brunnhuber (kbrunnhuber@ bmigroup.com).

\section{Call for peer reviewers}

Clinical Evidence also needs to recruit a number of new peer reviewers specifically with an interest in the clinical areas stated above, and also others related to general practice. Peer reviewers are healthcare professionals or epidemiologists with experience in evidence-based medicine. As a peer reviewer you would be asked for your views on the clinical relevance, validity, and accessibility of specific topics within the journal, and their usefulness to the intended audience (international generalists and healthcare professionals, possibly with limited statistical knowledge). Topics are usually 1500-3000 words in length and we would ask you to review between 2-5 topics per year. The peer review process takes place throughout the year, and our turnaround time for each review is ideally 10-14 days.

If you are interested in becoming a peer reviewer for Clinical Evidence, please complete the peer review questionnaire at www.clinicalevidence.com or contact Klara Brunnhuber (kbrunnhuber@bmigroup.com). 